\title{
Prescribing by Pharmacists: Information Paper (2009)
}

\author{
Pharmacist Prescribing Task Force
}

This Information Paper was developed to inform pharmacists and nonpharmacists about the practice of prescribing by pharmacists. In doing so, it should support pharmacists in their attempts to expand their practices into the area of prescribing. As an information paper, it does not provide an outline of conduct or detailed guidelines on how pharmacists should prescribe. It replaces the CSHP "Information Paper on Pharmacist Prescribing in a Health Care Facility", which was approved in 2001. The current document was approved by CSHP Council as an official CSHP publication in August 2009 and is a companion to the CSHP "Prescribing by Pharmacists: Statement", which was approved at the same time.

\section{INTRODUCTION}

Ч istorically, patients have relied on physicians and dentists 1 to prescribe medications, order laboratory tests, and conduct or supervise procedures consistent with the patients' diagnoses. More recently, prescribing privileges have been extended to other healthcare professionals, such as nurse practitioners, nurses with an expanded scope of practice, clinical nurse specialists, registered midwives, dieticians, podiatrists, optometrists, and, in many jurisdictions, pharmacists. The impetus for these advanced professional roles is to improve patients' access to care, by optimizing the roles of healthcare providers.

Healthcare in Canada has undergone significant changes in the past few decades and will continue to evolve to meet the dynamic needs of the population. Both the Commission on the Future of Healthcare in Canada ${ }^{1}$ (the Romanow Commission) and the Saskatchewan Commission on Medicare ${ }^{2}$ (the Fyke Commission) emphasized the importance of multidisciplinary healthcare teams working together to improve the efficiency and accessibility of patient care. Such teamwork reduces duplication of effort among healthcare professionals and optimizes the use of each profession's unique knowledge and skills.

Pharmacy has evolved from a profession with a productfocused practice to one with a patient-focused practice. Largescale pharmaceutical manufacturing, the expanded use of automation, and the broader role and more widespread employment of pharmacy technicians to perform routine dispensing activities has enabled pharmacists to shift their focus from compounding and dispensing medications to optimizing patients' healthcare outcomes. This shift was defined through the concept of pharmaceutical care, in which the pharmacist assumes responsibility for a patient's medication-related needs. ${ }^{3}$ More recently, the Blueprint for Pharmacy: The Vision for Pharmacy ${ }^{4}$ envisions Canadians achieving "optimal drug therapy outcomes through patient-centred care" (p. 4) in which pharmacists "practise to the full extent of their skills and knowledge" (p. 4).

Like other healthcare professionals, pharmacists have a responsibility to work toward establishing a better healthcare system, one that will improve the outcomes and costeffectiveness of drug therapy. It has been postulated that granting prescribing authority to pharmacists could lead to such improvements. Decreasing the number of steps that a patient must take to obtain the optimal medication regimen can help in medication management and continuity of care. ${ }^{5}$ Strategies to reduce the time a patient remains in hospital and to eliminate inefficiencies and duplication of effort by health-

Members of the Pharmacist Prescribing Task Force: Tania M Mysak, BSP, PharmD (Chair); Corrine Clarke, BScPharm; Sue Corrigan, BScPharm, ACPR, PharmD; Margaret Gray, BSP; Michael P Namaka, BScPharm, PhD; Shannan Neubauer, BSP, PharmD, ACPR, FCSHP; Carmine Stumpo, BScPhm, PharmD; Roxane Therrien, BPharm, MSC; Jeff Whissell, BScPharm, ACPR; Erin M Yakiwchuk, BSP, ACPR; Nese Yuksel, BSCPharm, PharmD, ACPR, FCSHP, NCMP. Ex officio members: Jason M Howorko, BSP, BSC, ACPR (CSHP President Elect, at the time of writing); Catherine A Lyder, BScPharm, MHSA (CSHP Coordinator, Professional and Membership Affairs). 
care professionals are being developed and implemented throughout Canada. Pharmacists are increasingly aware that the current process of providing healthcare frequently results in outcomes that are not as effective, appropriate, safe, or economical as desirable. In response, researchers have tried to assess the effects of pharmacists providing direct patient care on relevant end points such as patient outcomes, readmission to hospital, morbidity, mortality, and cost of care. For example, clinical pharmacy services have been associated with improvements in patient safety through reductions in medication errors and decreases in mortality. ${ }^{6}$ Inclusion of a pharmacist on clinical teams has led to improved patient outcomes, decreased length of stay in hospital, and reduced costs. ${ }^{7-10}$ Finally, prescribing by pharmacists in collaborative practice models improved patients' outcomes in several studies. ${ }^{11-14}$

Some commentators have suggested that if pharmacists are to fully implement direct patient care, every pharmacist should have the authority to maximize the use of their extensive drug knowledge by prescribing drugs. ${ }^{15}$ Ultimately, patient care and patients' outcomes would be improved with such an expansion of practice. Therefore, the goal of prescribing by pharmacists is to improve the health of Canadians by optimizing the use of pharmacists' expertise and knowledge. In recognition of the potential impact that prescribing by pharmacists could have on patient care and patients' outcomes, legislation and practice models are evolving across Canada to accommodate this activity.

This paper has three main objectives:

1) To define prescribing and to describe the many methods by which pharmacists currently prescribe.

2) To review experiences with prescribing by pharmacists, both internationally and in Canada.

3) To describe the general components required for pharmacists to prescribe safely and responsibly.

\section{DESCRIPTION OF PRESCRIBING BY PHARMACISTS}

\subsection{Definition of Prescribing}

The act of prescribing medications has been defined in various ways by different authorities. For the purposes of this paper, the definition from Stedman's Medical Dictionary ${ }^{16}$ is used: "to give directions, either orally or in writing, for the preparation and administration of a remedy to be used in the treatment of any disease". This activity is separate from "diagnosing", which is defined as "the determination of the nature of a disease, injury, or congenital defect" ${ }^{16}$ Although the act of prescribing depends upon a diagnosis, these two activities need not be performed by the same healthcare professional.

Assessing patients, managing medications, and monitoring care are core elements of pharmacists' practice in all care settings (community and institutional). This combination of activities may translate into different types of prescribing, reflecting both the patient's health needs and the collaborative professional environment in which the pharmacist practises. Some examples of situations in which pharmacists prescribe are outlined below. The terms used (e.g., "adapting" versus "altering") may differ by province or by country.

\subsection{Initial-Access Prescribing}

Pharmacists form a widely accessible group of primary care practitioners who can effectively manage minor diseases and conditions and some emergency situations. Initial-access prescribing occurs when a patient approaches a pharmacist for advice and treatment of minor conditions, for information about health promotion, and in emergency or urgent situations. ${ }^{17}$ A self-medication consultation begins with a pharmacist's assessment of the patient's signs, symptoms, history, and precipitating factors to determine if the disease or condition requires treatment. If a nonprescription drug therapy or a nondrug therapy is appropriate, the pharmacist prescribes the treatment and recommends appropriate followup. If further diagnostic evaluation is necessary, the pharmacist refers the patient to the appropriate healthcare professional.

Prescribing in an emergency situation is familiar to all pharmacists. Whether they are providing medication refills pending the patient's next visit to his or her physician, extending the stop date of a long-term medication in a hospital setting, or providing emergency contraception, pharmacists have worked for many years to meet the emergency needs of the patients within their care. The underlying premise for prescribing in an emergency situation is to offer patients effective, timely access to care. Legislative changes in many provinces have already made this component of pharmacists' practice routine.

\subsection{Adapting a Prescription}

During the process of reviewing a prescription, a pharmacist may identify a problem with a prescription written by another healthcare professional. ${ }^{3}$ To improve the overall outcomes of drug therapy or to provide continuity of therapy, the pharmacist may modify the pre-existing prescription, thus supporting safe and effective medication use. Such modifications may include alteration of the formulation, dose, regimen, or duration of therapy, or they may involve therapeutic interchange, with the general goal of providing patient-centred care. An incredible variety and complexity of medications are available today, and pharmacists, with their in-depth knowledge of these compounds, represent an essential expert resource in ensuring that medication therapy has optimal outcomes.

\subsection{Comprehensive Medication Management}

Comprehensive medication management for a known diagnosis may include the following steps: selecting appropriate drug therapy according to patient-specific factors; prescribing 
drug therapy, initiating a monitoring plan, modifying therapy on the basis of ongoing assessments, and discontinuing therapy if deemed appropriate. It may also involve referral to other members of the collaborative team if necessary to achieve the best possible outcomes for patients. Pharmacists working in a collaborative setting with other members of the healthcare team are in an ideal position to be responsible for the ongoing management of patients' drug therapy.

\subsection{Pharmacists as Prescribers}

As demonstrated above, the practice settings in which pharmacists are able to prescribe are as varied as the practices themselves. Pharmacists in both inpatient and ambulatory clinic practices work within interdisciplinary teams. In these settings the pharmacist serves as the team's resource for medication management. Prescribing for patients in this setting is a natural extension of this role. Prescribing may also occur in a dispensary facility, where pharmacists' knowledge of their patients may be incomplete because of limited access to patients and their health records. Nonetheless, pharmacists are often able to assess the appropriateness of a patient's medications on the basis of information available in the patient's medication profile (such as organ function, drug interactions, and allergies). Although prescribing in these settings is less than ideal, it still affords an approach to improving patient care, ensuring that the pharmacist maintains open and clear communication of all prescription changes and the rationale for them.

Regardless of the setting, models of prescribing by pharmacists have been developed with the ultimate goals of improving patients' access to care and using pharmacists to the full scope of their skills and abilities.

\section{EXPERIENCE WITH PRESCRIBING BY PHARMACISTS}

\subsection{Review of Worldwide Experience}

Various models of prescribing by pharmacists exist around the world. In a recent global survey on hospital pharmacy practice, 20 (24\%) of 85 responding countries reported that pharmacists prescribed medications in hospitals under certain circumstances (such as an agreement with a physician). ${ }^{18}$

The United Kingdom has two models of prescribing, known as supplementary and independent prescribing. Supplementary prescribing, a form of dependent prescribing, came into effect in 2003. ${ }^{19}$ In this model, a pharmacist (the supplementary prescriber) enters into an agreement with an independent prescriber (a physician) to implement a patientspecific care plan for a medical condition diagnosed by the physician. In May 2006, the relevant legislation was expanded to give pharmacists independent prescribing authority. ${ }^{19}$ In the United States, pharmacists in 45 states are authorized to manage medications under a physician's guidance through various collaborative drug therapy management agreements. ${ }^{20-24}$ Similarly, in New Zealand, registered healthcare professionals can enter into dependent prescribing arrangements with authorized prescribers through standing orders or protocols. ${ }^{25}$

\subsection{Review of Canadian Experience}

Several government commissions, pharmacist regulatory authorities and associations, and other organizations across Canada have been advocating for a generally enhanced role for pharmacists. ${ }^{1,2,26,27}$ The prescribing authority given to pharmacists has evolved over the past decade. ${ }^{28}$ Across Canada, the provinces are at different stages of adopting or changing legislation to expand prescribing rights for pharmacists (Appendix A). ${ }^{22}$ Currently, regulations vary among provinces, with the types of prescribing authority granted to pharmacists ranging from renewing or adapting prescriptions (e.g., British Columbia, Nova Scotia, Saskatchewan, and Quebec) and prescribing in emergencies (e.g., Alberta and New Brunswick) to initiating or managing ongoing therapy (e.g., Alberta, Manitoba, and Quebec). The requirements for prescribing also differ between provinces. For example, in Alberta, all pharmacists have basic prescribing rights (i.e., for adaptation and emergency prescribing), but "additional prescribing authorization" requires a detailed, peer-reviewed application to the Alberta College of Pharmacists. In that province, pharmacists with "additional prescribing authorization" are able to initiate, monitor, modify, and manage medication therapy as appropriate at the time of initial access or in collaboration with another healthcare professional..$^{22}$ In contrast, pharmacists in Manitoba must make a detailed application to the College of Physicians and Surgeons of Manitoba.

For years, pharmacists have performed many types of prescribing within Canadian institutional settings, such as pharmacokinetic dosing services and therapeutic interchange. ${ }^{29}$ Interestingly, according to the latest Hospital Pharmacy in Canada survey (for 2007/2008), ${ }^{28}$ the proportion of hospitals that reported prescribing by pharmacists increased since the previous survey in 2005/2006 (61\% [99/163] versus 46\% [66/142]). The majority of the activity was for dosage adjustments through "dependent" prescribing (79\%), such as medication management protocols or automatic substitutions. ${ }^{28}$

\section{SAFE AND RESPONSIBLE PRESCRIBING}

The achievement of optimal patient outcomes requires that prescribing be done safely and responsibly. Whether the pharmacist is recommending a nonprescription product to an ambulatory patient, adjusting the prescription for an antibiotic 
because of decreased renal function, or initiating lipid-lowering therapy in a patient at high risk for cardiovascular disease, certain practice components contribute to safety and optimal care. These components include appropriate legislation and policy, the prescriber's competence, access to appropriate and sufficient information about the patient (e.g., medical and medication history, health goals), a relationship with the patient, collaboration and communication with other healthcare professionals, and comprehensive documentation. Underpinning each of these components is the pharmacist's responsibility for his or her actions.

\subsection{Legislation and Policy}

Legislation and policy can support safe and responsible healthcare by authorizing pharmacists to practise to the full extent of their knowledge and skills. Pharmacists work in a variety of practice environments and hence may be subject to additional policies or directives within their respective employer organizations, beyond those set by legislation. Such policies, directives, and procedures must be aligned with the relevant provincial legislation to allow pharmacists to work to their full scope of practice.

\subsection{Competence of Individual Prescribers}

In Canada, all pharmacists must complete an undergraduate university degree from a school of pharmacy and must have some practical experience before entering practice. In addition, many pharmacists continue their formal training through residencies, graduate studies, and postgraduate fellowships. Recognizing the evolving role of the pharmacist, pharmacy faculties in Canada have increased clinical training and experiential learning. Patient care skills are learned and enhanced through hands-on experience with patients and the mentoring that pharmacy students and pharmacists receive from their peers and other healthcare professionals.

In addition to this formal learning, provincial pharmacy regulatory authorities require licensed pharmacists to continually maintain and upgrade their knowledge and skills, regardless of whether they prescribe. A key component of continuing education is self-evaluation. As such, pharmacists are well placed to critically evaluate their own knowledge, skill sets, and practice environment to ensure that they are practising both to their full scope of practice and within the limits of their individual competence.

\subsection{Access to Patient Information}

Safe and responsible prescribing involves making the most appropriate decision regarding drug therapy, with pertinent patient information at hand. Having up-to-date laboratory results, progress notes, medication profile, medication history, and medical history that can be accessed by multiple healthcare providers enhances collaboration and the sharing of relevant information. Like all other healthcare professionals, pharmacists are expected to protect the confidentiality of patient information, as required by provincial regulations and ethical obligations.

\subsection{Relationship with Patient}

Patient care is best practised when the needs and goals of the individual patient are the guiding elements. In providing patient-centred care, the care provider first establishes a relationship with the patient. This is clearly stated as the first step in the pharmaceutical care process. ${ }^{3}$ Although the nature of the relationship may vary according to the complexity of the care being provided, the role of the pharmacist can be clearly described to the patient, such that the patient will have the opportunity to express his or her needs and goals.

The relationship between the patient and the pharmacist is not a substitute for the patient's relationship with other healthcare providers, and any given patient may have care relationships with a variety of care providers. Ideally, open communication and a collaborative spirit will allow these relationships to be complementary, each one enhancing the others.

\subsection{Collaboration with Other Healthcare Providers}

Within the healthcare team, pharmacists possess a unique skill set and knowledge base related to the use of medications. These attributes complement those of other healthcare providers, and, when they are exercised in a collaborative environment, patient care is optimized. ${ }^{6,9}, 10$ For many healthcare professionals, the environment in which they practise is becoming more collaborative. This positive step can be encouraged and fostered by keeping the goal of patient safety paramount. Optimizing interactions among healthcare professionals will allow each profession to more fully appreciate the contributions that the others make and will allow for mutual support. Even if providers do not work in the same physical space, resources and energy can be directed toward timely and effective communication between providers by utilizing technology more fully.

\subsection{Documentation and Communication}

Legislation requires the pharmacist to document the care provided in a patient record. Proper documentation is essential for maintaining an ongoing record of interventions and care, and for communicating care plans to other healthcare professionals. Practice environments can be modernized and technology fully integrated to enhance and facilitate the sharing 
of information. Use of standardized technology and clear policies and procedures for documentation can do much to ensure patient safety and facilitate care.

\subsection{Responsibility}

An underlying theme in the above components of care is responsibility. As defined by Hepler and Strand, ${ }^{3}$ pharmaceutical care is "the responsible provision of drug therapy for the purpose of achieving definite outcomes that improve a patient's quality of life".

Thus, pharmacists practising according to this model of care will be responsible in all facets, from establishing a relationship with the patient and setting patient-specific goals to documenting and monitoring the patient's care plan. As well, pharmacists are expected to work within their respective scopes of practice and to follow their respective provincial codes of ethics.

With increased authority comes increased accountability. As pharmacists practise within new scopes of practice, it will be their responsibility to ensure that they have the appropriate liability coverage for their individual practice.

\section{CONCLUSION}

Pharmacist practice has evolved to facilitate better patient care; prescribing is one tool to facilitate the delivery of safe and effective healthcare. Prescribing by pharmacists can take a variety of forms, including initial-access prescribing, prescribing in emergency situations, adapting prescriptions, and performing comprehensive medication management. Most Canadian provinces now have legislative support for some form of prescribing by pharmacists. Key components that ensure safe and successful pharmacist prescribing include adequate access to patient information, the establishment of a relationship with the patient, collaboration with other healthcare providers, documentation, communication, and individual responsibility. Ultimately, pharmacist prescribing improves patient care by improving access to care and using pharmacists to their full scope of practice.

\section{LITERATURE CITED}

1. Romanow RJ, commissioner; Commission on the Future of Health Care in Canada. Building on values: the future of health care in Canada - final report. Saskatoon (SK): The Commission; 2002 [cited 2009 Feb 28]. Available from: http://www.cbc.ca/healthcare/final_report.pdf

2. Fyke KJ, commissioner; Commission on Medicare. Caring for medicare: sustaining a quality system. Regina (SK): Government of Saskatchewan; 2001 [cited 2009 Feb 28]. Available from: http://www.health.gov.sk.ca/medicare-commissionfinal-report
3. Hepler CD, Strand L. Opportunities and responsibilities in pharmaceutical care. Am J Hosp Pharm 1990;47(3): 533-543.

4. Blueprint for pharmacy. The vision for pharmacy: optimal drug therapy outcomes for Canadians through patient-centred care. Ottawa (ON): Canadian Pharmacists Association; 2008 [cited 2009 Jul 10]. Available from: http:// www.pharmacists.ca/ content/about_cpha/whats_happening/cpha_in_action/pdf/ BlueprintVision.pdf

5. Galt KA. The key to pharmacist prescribing: collaboration. Am J Health Syst Pharm 1995;52(15):1696-1699.

6. Bond CA, Raehl CL. Clinical pharmacy services, pharmacy staffing, and hospital mortality rates. Pharmacotherapy 2007;27(4):481-493.

7. Makowsky MJ, Koshman SL, Midodzi WK, Tsuyuki RT. Capturing outcomes of clinical activities performed by a rounding pharmacist practicing in a team environment: the COLlABORATE Study. Med Care 2009;47(6):642-650.

8. Gillespie U, Alassaad A, Henrohn D, Garmo H, Hammarlund-Udenaes $\mathrm{M}$, Toss $\mathrm{H}$, et al. A comprehensive pharmacist intervention to reduce morbidity in patients 80 years or older: a randomized controlled trial. Arch Intern Med 2009;169(9):894-900.

9. Kaboli PJ, Hoth AB, McClimon BJ, Schnipper JL. Clinical pharmacists and inpatient medical care: a systematic review. Arch Intern Med 2006;166(9):955-964.

10. Kucukarslan SN, Peters M, Mlynarek M, Nafziger DA. Pharmacists on rounding teams reduce preventable adverse drug events in hospital general medicine units. Arch Intern Med 2003; 163(17):2014-2018.

11. Finley PR, Rens HR, Pont JT, Gess SL, Louie C, Bull SA, et al. Impact of a collaborative pharmacy practice model on the treatment of depression in primary care. Am J Health Syst Pharm 2002;59(16):1518-1526.

12. Dole EJ, Murawski MM, Adolphe AB, Aragon FD, Hochstadt B. Provision of pain management by a pharmacist with prescribing authority. Am J Health Syst Pharm 2007;64(1):85-89.

13. McKenney JM, Slining JM, Henderson HR, Devins D, Barr M. The effect of clinical pharmacy services on patients with essential hypertension. Circulation 1973;48(5):1104-1111.

14. Stimmel GL, McGhan WF, Wincor MZ, Deandrea DM. Comparison of pharmacist and physician prescribing for psychiatric inpatients. Am J Hosp Pharm 1982;39(9): 1483-1486.

15. Williams DH. R.Ph. prescribing: a natural step forward. Drug Top 1994 Sep 19;:10.

16. Stedman's medical dictionary. 27th ed. Baltimore (MD): Lippincott Williams \& Wilkins; 2000.

17. What is pharmacist prescribing? Edmonton (AB): Alberta College of Pharmacists; 2008 [cited 2009 Jul 6]. Available from: https://pharmacists.ab.ca/nPublic/PharmacistPrescribing.aspx

18. Doloresco F, Vermeulen LC. Global survey of hospital pharmacy practice. Am J Health Syst Pharm 2009;66(5 Suppl 3):S13-S19.

19. Tonna AP, Stewart D, West B, McCaig D. Pharmacist prescribing in the UK - a literature review of current practice and research. J Clin Pharm Ther 2007;32(6):545-556.

20. Traynor K. Pharmacists outside U.S. inch toward independent prescribing. Am J Health Syst Pharm 2004; 61(14):1429.

21. Status of collaborative drug therapy management in the United States, March 2004. Am J Health Syst Pharm 2004; 61(15): 1609-1610. 
22. Yuksel N, Eberhart G, Bungard TJ. Prescribing by pharmacists in Alberta. Am J Health Syst Pharm 2008; 65(22): 2126-2132.

23. Meyer B, Hill J, Trujillo G. Attaining pharmacist recognition in the United States. Am J Health Syst Pharm 2008; 65(22):21522153.

24. Hammond RW, Schwartz AH, Campbell MJ, Remington TL, Chuck S, Blair MM, et al.; American College of Clinical Pharmacy. Collaborative drug therapy management by pharmacists - 2003. Pharmacotherapy 2003; 23(9):1210-1225.

25. Emmerton L, Marriott J, Bessell T, Nissen L, Dean L. Pharmacists and prescribing rights: review of international developments. J Pharm Pharm Sci 2005;8(2):217-225.

26. Saskatchewan College of Pharmacists position statement on enhanced authority for the pharmacist to prescribe drugs in collaborative practice environments. Regina (SK): Saskatchewan College of Pharmacists; 2008.

27. Health Professions Regulatory Advisory Committee. An interim report to the Minister of Health and Long-Term Care on mechanisms to facilitate and support interprofessional collaboration among health colleges and regulated health professionals: phase II, part I. Toronto (ON): The Committee; 2008 [cited 2009 Jul 6]. Available from: http://www.hprac.org/en/projects/resources/ InterprofessionalCollaborationReportPhaseIIPartIENGSept08.pdf

28. Babich M, Bussières JF, Hall KW, Harding J, Johnson N, Lefebvre P, et al., editors. Hospital pharmacy in Canada 2007/2008 report. Eli Lilly; 2008 [cited 2009 Mar 16]. Available from: http://www.lillyhospitalsurvey.ca/hpc2/content/rep_2008_ toc.asp

29. Hospital pharmacists - enhancing quality and safety in medication use. Ottawa (ON): Canadian Society of Hospital Pharmacists; 2009 [cited 2009 Jul 3]. Available from: http://www.cshp.ca/ dms/dmsView/1_Hospital-Pharmacists---Enhancing-QualityBkgrnd-Doc---FINAL.pdf

\section{ADDITIONAL RESOURCES}

Berry M. Comparison of the practice of pharmacy - prescribing authority -8.490 . In: Canadian pharmacy law. Aurora (ON): Canada Law Book; 2008. Release No 27.

$\mathrm{CPhA}$ position statement on pharmacist prescribing. Ottawa (ON): Canadian Pharmacists Association; 2007 [cited 2009 Feb 28]. Available from: http://www.pharmacists.ca/content/about_ cpha/who_we_are/policy_position/pdf/CPhA\%20position $\% 20$ s tatement $\% 20$ Pharmacist $\% 20$ Prescribing\%20Final2\%20August \%2007.pdf

FIP Global Conference on the Future of Hospital Pharmacy: final Basel statements. The Hague (Netherlands): International Pharmaceutical Federation; 2008 [cited 2009 Jul 10]. Available from: http://www.fip.org/files/congress/globalhosp2008/Final\% 20Basel\%20Statements\%2012-4-08\%20Formatted.pdf

Mosnia P. Emerging roles of the pharmacist: from dispensing to prescribing. Long Term Care 2008 Sep-Oct [cited 2009 Jun 3]. Available from: http://www.oltca.com/Library/LTC1008 Emerging_roles.pdf. Note: Publication available to members only. Optimal prescribing and medication use in Canada: challenges and opportunities. Ottawa (ON): Health Council of Canada; 2007.

Pearson GJ. Evolution in the practice of pharmacy - not a revolution! CMAJ 2007;176(9):1295-1296.

Pharmacist prescribing position statement. Vancouver (BC): British Columbia Pharmacy Association; 2007 [cited 2009 Feb 28]. Available from: http://www.bcpharmacy.ca/press_room/documents/ PositionStatement-PharmacistPrescribing.pdf

Regulations of the New Brunswick Pharmaceutical Society. Moncton (NB): New Brunswick Pharmaceutical Society; 2009 [cited 2009 Mar 17]. Available from: http:// www.nbpharmacists.ca/ LinkClick.aspx?fileticket=hXAY\%2bPlAkQA\%3d \&tabid=244 \&mid $=686$ 


\section{Appendix A: Prescribing By Pharmacists in Canada, 2009}

\begin{tabular}{|c|c|c|c|c|}
\hline $\begin{array}{l}\text { Province or } \\
\text { territory }\end{array}$ & $\begin{array}{l}\text { Relevant } \\
\text { legislation }\end{array}$ & $\begin{array}{l}\text { Prescribing privileges or } \\
\text { type of prescribing }\end{array}$ & $\begin{array}{l}\text { Requirements } \\
\text { to prescribe }\end{array}$ & $\begin{array}{l}\text { Effective } \\
\text { date* }\end{array}$ \\
\hline British Columbia & $\begin{array}{l}\text { Bill-25: Health } \\
\text { Professions Amendment } \\
\text { Act } 2008\end{array}$ & $\begin{array}{l}\text { Prescribe in an emergency, adapt a } \\
\text { prescription (renewals, dose or } \\
\text { formulation adjustments, and } \\
\text { therapeutic substitutions) }\end{array}$ & $\begin{array}{l}\text { Registered pharmacists, } \\
\text { upon completion of } \\
\text { orientation session }\end{array}$ & Jan 2009 \\
\hline Alberta & Health Professions Act & $\begin{array}{l}\text { Prescribe in an emergency, adapt a } \\
\text { prescription (renewals, dose or } \\
\text { formulation adjustments, and } \\
\text { therapeutic substitutions) } \\
\text { Additional prescribing authorization } \\
\text { (initiate or manage ongoing therapy) }\end{array}$ & $\begin{array}{l}\text { Pharmacists on the ACP } \\
\text { clinical register, upon } \\
\text { completion of the } \\
\text { orientation to new standards } \\
\text { Pharmacists who have been } \\
\text { given authorization after } \\
\text { application to ACP }\end{array}$ & Apr 2007 \\
\hline Saskatchewan & $\begin{array}{l}\text { The Pharmacy Act } \\
\text { Bill 22, An Act to } \\
\text { Amend The Pharmacy } \\
\text { Act (1996) }\end{array}$ & $\begin{array}{l}\text { Emergency contraception } \\
\text { SCP can create supporting bylaws for } \\
\text { prescribing by pharmacists } \\
\text { Proposed: } \\
\text { Level I Authority Prescribing - refills, } \\
\text { continuing therapy, emergency } \\
\text { medications, medications for } \\
\text { self-care, nonprescription medications } \\
\text { (for third party), seamless care } \\
\text { Level II Authority Prescribing - } \\
\text { independent, collaborative } \\
\text { agreements; therapeutic substitution; } \\
\text { dosage adjustments }\end{array}$ & $\begin{array}{l}\text { All registered pharmacists, } \\
\text { with additional training } \\
\text { Level I - all registered } \\
\text { pharmacists } \\
\text { Level II - pharmacists with } \\
\text { additional training } \\
\text { (evidence of proper } \\
\text { training must be } \\
\text { submitted) }\end{array}$ & TBA \\
\hline Manitoba & $\begin{array}{l}\text { Bill 41: The } \\
\text { Pharmaceutical Act }\end{array}$ & $\begin{array}{l}\text { Continued care prescription (renewal } \\
\text { or refill of a prescription) } \\
\text { New regulations will include provisions } \\
\text { to prescribe and administer drugs, } \\
\text { to interpret results of point-of-care } \\
\text { patient self-tests, and to order and } \\
\text { receive results for screening and } \\
\text { diagnostic tests (pending acceptance } \\
\text { by a majority vote of pharmacists } \\
\text { registered in Manitoba). }\end{array}$ & $\begin{array}{l}\text { All registered pharmacists } \\
\text { Extended practice - } \\
\text { application to MPhA } \\
\text { Clinical assistant specialist - } \\
\text { registered under The } \\
\text { Medical Act (can currently } \\
\text { prescribe) }\end{array}$ & TBA \\
\hline Ontario & $\begin{array}{l}\text { Regulated Health } \\
\text { Professions Act }\end{array}$ & $\begin{array}{l}\text { Interim report from HPRAC } \\
\text { recommended authority to prescribe } \\
\text { for minor ailments, to extend } \\
\text { prescriptions, to adapt prescriptions } \\
\text { on the basis of laboratory test results, } \\
\text { and to administer drugs. Prescribing } \\
\text { is referred to as "professional } \\
\text { collaboration". }\end{array}$ & Under development & TBA \\
\hline Quebec & $\begin{array}{l}\text { Bill 90: An Act to } \\
\text { Amend the Professional } \\
\text { Code }\end{array}$ & $\begin{array}{l}\text { Initiate or adjust medication therapy } \\
\text { according to a prescription by a } \\
\text { physician (authorizing the } \\
\text { pharmacist), prescribe emergency } \\
\text { contraception }\end{array}$ & $\begin{array}{l}\text { All registered pharmacists } \\
\text { (specific training required } \\
\text { for emergency } \\
\text { contraception) }\end{array}$ & Jan 2003 \\
\hline New Brunswick & $\begin{array}{l}\text { Bill 60: An Act to } \\
\text { Amend the Pharmacy } \\
\text { Act }\end{array}$ & $\begin{array}{l}\text { Renew or extend prescriptions, adapt } \\
\text { prescriptions under certain conditions, } \\
\text { prescribe in emergencies, and initiate } \\
\text { therapy for pre-existing conditions }\end{array}$ & All registered pharmacists & Oct 2008 \\
\hline Nova Scotia & Pharmacy Act S.80 & $\begin{array}{l}\text { Conditional authority (written } \\
\text { agreements with College of } \\
\text { Physicians and Surgeons of } \\
\text { Nova Scotia) } \\
\text { Extend prescriptions } \\
\text { Further regulations to expand practice } \\
\text { are under development }\end{array}$ & All registered pharmacists & 2006 \\
\hline $\begin{array}{l}\text { Prince Edward } \\
\text { Island }\end{array}$ & $\begin{array}{l}\text { Bill 10: An Act to } \\
\text { Amend the Pharmacy } \\
\text { Act }\end{array}$ & $\begin{array}{l}\text { Act added "giving prescription for a } \\
\text { drug" to the practice of pharmacy; } \\
\text { regulations currently under } \\
\text { development }\end{array}$ & Under development & TBA \\
\hline
\end{tabular}


Appendix A: Prescribing By Pharmacists in Canada, 2009 (continued)

\begin{tabular}{|c|c|c|c|c|}
\hline $\begin{array}{l}\text { Province or } \\
\text { territory }\end{array}$ & $\begin{array}{c}\text { Relevant } \\
\text { legislation }\end{array}$ & $\begin{array}{l}\text { Prescribing privileges or } \\
\text { type of prescribing }\end{array}$ & $\begin{array}{l}\text { Requirements } \\
\text { to prescribe }\end{array}$ & $\begin{array}{l}\text { Effective } \\
\text { date* }\end{array}$ \\
\hline $\begin{array}{l}\text { Newfoundland } \\
\text { and Labrador }\end{array}$ & The Pharmacy Act & $\begin{array}{l}\text { Under discussion; changes } \\
\text { to the Act have not yet been } \\
\text { proposed }\end{array}$ & NA & NA \\
\hline $\begin{array}{l}\text { Northwest } \\
\text { Territories }\end{array}$ & $\begin{array}{l}\text { Pharmacy Act, S.N.W.T. } \\
2006, \text { c. } 24 \\
\text { Adoption of Formulary } \\
\text { for the Substitution of } \\
\text { Pharmaceutically } \\
\text { Equivalent Drugs Order, } \\
\text { N.W.T. Reg. 028-2007 } \\
\text { Pharmacy Regulations, } \\
\text { N.W.T. Reg. 018-2007 }\end{array}$ & $\begin{array}{l}\text { Immediate need for refill } \\
\text { Substitute a pharmaceutically } \\
\text { equivalent drug for the drug } \\
\text { prescribed by the practitioner, in } \\
\text { accordance with the territory's } \\
\text { formulary } \\
\text { Modify or include instructions in } \\
\text { respect of medical devices or } \\
\text { packaging requirements }\end{array}$ & All registered pharmacists & 2007 \\
\hline Nunavut & Pharmacists Act & Cannot prescribe & NA & NA \\
\hline Yukon & Pharmacists Act & Cannot prescribe & NA & NA \\
\hline
\end{tabular}

Abbreviations: $\mathrm{ACP}=$ Alberta College of Pharmacists, SCP = Saskatchewan College of Pharmacy, HPRAC = Health

Professions Regulatory and Advisory Council, NA = not applicable, MPhA = Manitoba Pharmaceutical Association,

TBA = to be announced.

*Date of implementation of regulations.

\section{Bibliography}

An Act to Amend the Pharmacy Act, S.P.E.I. 2008, c. 24 [cited 2009 Jun 29]. Available from: http://www.assembly.pe.ca/bills/ onebill.php? session=2\&generalassembly=63\&number $=10$

Amendment to orientation guide - medication management (adapting a prescription). Vancouver (BC): College of Pharmacists of British Columbia; 2008 [cited 2009 Jun 29]. Available from: http://www.bcpharmacists.org/library/D-Legislation_Standards/

D-2_Provincial_Legislation/PPP58_AmendmentOrientationGuide.pdf

Expand your scope [website]. Pharmacy Gateway (Rogers Publishing Limited); 2009 [cited 2009 Jul 6]. Available http://www.pharmacygateway.ca/microsite/expandyourscope/index.html Note: Comprehensive summary of provincial legislation.

FAQ's for pharmacists on prescribing. Moncton (NB): New Brunswick Pharmaceutical Society; 2008 [cited 2009 Mar 17]. Available from: http://www.nbpharmacists.ca/FAQsforPharmacistsonprescribing/tabid/473/language/en-CA/Default.aspx

Felix S. The law on your side. Expanded Horizons. Pharmacy Practice [Rogers Publishing Limited] 2008;24(10 suppl):23-30.

Health Professions Regulatory Advisory Committee. An interim report to the Minister of Health and Long-Term Care on mechanisms to facilitate and support interprofessional collaboration among health colleges and regulated health professionals: phase II, part I. Toronto (ON): The Committee; 2008 [cited 2009 Jul 6]. Available from: http://www.hprac.org/en/projects/resources/InterprofessionalCollaborationReport PhaseIIPartIENGSept08.pdf

Interprofessional collaboration: pharmacy scope of practice. Jurisdictional review. Toronto (ON): Health Professions Regulatory Advisory Council; 2008 [cited 2009 Jul 6]. Available from: http://www.hprac.org/en/projects/resources/PHARMACY-ScopeJurisdictionalReview.pdf

Lynas K. Ontario advisory body recommends that pharmacists be granted authority to prescribe for minor ailments. Can Pharm J 2009;142(1):9. Pharmacy Act, S.N.W.T. 2006, c. 24 [cited 2009 Jul 10]. Available from: http://www.justice.gov.nt.ca/PDF/ACTS/Pharmacy.pdf Pharmacy Act, R.S.N.W.T. 1988, c. P-6 [cited 2009 Jul 6]. Available from: http://www.canlii.org/nu/laws/sta/p-6/20070904/whole.html Pharmacists Act, R.S.Y. 2002, c. 170 [cited 2009 Jul 6]. Available from: http://www.canlii.org/yk/laws/sta/170/20060728/whole.html

Saskatchewan College of Pharmacists position statement on enhanced authority for the pharmacist to prescribe drugs in collaborative prescribing environments. Regina (SK): Saskatchewan College of Pharmacists; 2008 [cited 2009 Mar 17]. Available from:

http://www.saskcollegepharm.ca/docs/pharmacist_prescribing.pdf

What is pharmacist prescribing? Edmonton (AB): Alberta College of Pharmacists; 2008 [cited 2009 Jul 6]. Available from: https://pharmacists.ab.ca/nPublic/PharmacistPrescribing.aspx

Yuksel N, Eberhart G, Bungard TJ. Prescribing by pharmacists in Alberta. Am J Health Syst Pharm 2008;65(22):2126-2132. 